Research article

\title{
Primary biliary cirrhosis and autoimmune cholangitis are not associated with coeliac disease in Crete Costantinos Chatzicostas ${ }^{1}$, Maria Roussomoustakaki*1, Dimitrios Drygiannakis ${ }^{2}$, Maria Niniraki ${ }^{3}$, Maria Tzardi ${ }^{4}$, Mary Koulentaki1, Philippos Dimoulios ${ }^{1}$, Ioannis Mouzas ${ }^{1}$ and Elias Kouroumalis ${ }^{1}$
}

Address: ${ }^{1}$ Department of Gastroenterology, University Hospital of Heraklion, PO Box 1352, Heraklion 71110, Crete, Greece, ${ }^{2}$ Department of Immunology, Rethymnon General Hospital, Trantallidou 17, Rethymnon, Crete, Greece, ${ }^{3}$ Departments of Immunology, University Hospital of Heraklion, PO Box 1352, Heraklion 71110, Crete, Greece and ${ }^{4}$ Departments of Pathology, University Hospital of Heraklion, PO Box 1352, Heraklion 71110, Crete, Greece

E-mail: Costantinos Chatzicostas - matrix01gr@yahoo.gr; Maria Roussomoustakaki* - rousso@edu.uch.gr; Dimitrios Drygiannakis - jadrigmh@danae.med.uch.gr; Maria Niniraki - photeini@in.gr; Maria Tzardi - mrousso1@hotmail.com Mary Koulentaki - kofterid@med.uoc.gr; Philippos Dimoulios - fdimoul@hotmail.com; Ioannis Mouzas - mouzas@med.uoc.gr; Elias Kouroumalis - kouroum@med.uoc.gr

*Corresponding author

Published: 14 March 2002

BMC Gastroenterology 2002, 2:5

This article is available from: http://www.biomedcentral.com/|47|-230X/2/5

(c) 2002 Chatzicostas et al; licensee BioMed Central Ltd. Verbatim copying and redistribution of this article are permitted in any medium for any purpose, provided this notice is preserved along with the article's original URL.
Received: 4 January 2002

Accepted: 14 March 2002

\section{Abstract}

Background: An increased prevalence of coeliac disease in patients with primary biliary cirrhosis has been recently reported. However, in other studies the association has not been confirmed. There have been no formal attempts to systematically evaluate patients with autoimmune cholangitis for coeliac disease.

Methods: Sera from 62 patients with primary biliary cirrhosis, 17 with autoimmune cholangitis and 100 blood donors were screened for anti-gliadin, anti-endomysial, anti-reticulin, and IgA class antibodies to guinea pig liver-derived tissue transglutaminase. Eighteen untreated coeliacs served as methodological controls. Analyses were performed by using the $\chi^{2}$ and Fischer's exact tests.

Results: Anti-gliadin antibodies were detected in $21 \%$ of patients with primary biliary cirrhosis, $35 \%$ of patients with autoimmune cholangitis, and $3 \%$ of controls $(p<0.001$ ). IgA class gliadin antibodies positivity was more pronounced in patients with Scheuer's stage III-IV disease $(p<0.05)$. Anti-transglutaminase antibodies were detected in 10\% and in $18 \%$ of patients with primary biliary cirrhosis and autoimmune cholangitis respectively $(p<0.001)$. Anti-reticulin and anti-endomysial antibodies were negative in all patients. Duodenal biopsies were performed in $59 \%$ and $71 \%$ of patients with primary biliary cirrhosis and autoimmune cholangitis respectively, tested positive for at least one antibody class. No histological features of coeliac disease were found.

Conclusions: We were unable to demonstrate an increased risk of coeliac disease in patients with primary biliary cirrhosis and autoimmune cholangitis. Our results confirm the previously reported high prevalence of false-positive anti-gliadin and guinea pig liver-derived anti-tissue transglutaminase antibodies in patients with chronic liver disease. 


\section{Background}

Since the initial description of four patients with coeliac disease (CD) and primary biliary cirrhosis (PBC) [1], there have been several subsequent reports demonstrating an association of these two diseases [2-7]. Recently, a number of epidemiological studies reported an increased, up to $7 \%$, prevalence of $\mathrm{CD}$ in patients with $\mathrm{PBC}$ and an increased prevalence, up to $3 \%$, of $\mathrm{PBC}$ in patients with CD $[8,9]$. Screening for one disease when the other is identified has therefore been suggested. However, in other studies this association was found less pronounced or has not been confirmed [10-13]. Autoimmune cholangitis (AIC) was first reported as an overlap syndrome of autoimmune hepatitis and PBC, but is considered by most as a discrete entity of antimitochondrial antibody (AMA)negative $\mathrm{PBC}$ with autoimmune characters [14]. Apart from a case report [15], no relation of adult CD to autoimmune cholangitis has so far been described. However, there have been no formal attempts to systematically evaluate patients with AIC for $\mathrm{CD}$, presumably because AIC represents a rare form of chronic cholestatic liver disease.

Although a definite diagnosis of CD still requires histopathologic examination of the small intestinal mucosa, the screening methods for large number of individuals are based on non-invasive serological tests, namely, anti-gliadin (AGA, IgG and IgA class), anti-reticulin (ARA R1-type, IgA class) and anti-endomysial (EMA, IgA class) antibodies [16-18]. The combined use of serum IgG-AGA (good sensitivity) and IgA-EMA (good specificity) has resulted in a reliable screening test for diagnosis of CD [19]. However, anti-gliadin antibodies (AGAs) are not suitable for CD screening in patients with chronic liver diseases including $\mathrm{PBC}$, as an unacceptably high percentage of false-positives was reported in several studies $[11,20,21]$. In this respect, a previous study revealed that the serum IgA-EMA assay is the optimum test for predicting $\mathrm{CD}$ in patients with chronic liver disease [11]. Although IgA class antibodies to guinea pig liver-derived tissue transglutaminase (IgAtTG) have been shown to be highly specific and sensitive for the diagnosis of CD [22-26], it was recently reported that in patients with chronic liver disease there was a high frequency of false-positives which disappeared when human tTG was used as the antigen in the ELISA system [27]. In the present study we evaluated AGAs, IgA-ARA, IgAEMA and guinea pig liver-derived IgA-tTG in 62 patients with $\mathrm{PBC}$ and 17 patients with AIC. Intestinal biopsies have been subsequently performed in the majority of patients tested positive for at least one antibody class.

\section{Methods \\ Materials}

Serum samples from 62 patients with PBC (53 women and nine men; mean age, 59 years; range, $32-85$ years) and 17 patients with AIC (16 women and one man; mean age, 62 years; range, 52-77 years) were used in the study. The samples were collected prospectively over a $2 \mathrm{yr}$. period (1999-2000) and stored in aliquots at $-20^{\circ} \mathrm{C}$. Diagnosis of $\mathrm{PBC}$ was based on standard laboratory findings, compatible liver histology and the presence of AMA in titer $>1: 80$. Class 2 AMA antibodies (M2) detected by ELISA were positive in all patients. According to Scheuer's classification [28], 34 patients (54\%) had stage I-II and 28 (46\%) stage III-IV disease. The mean follow-up period from the time of diagnosis was 5.2 years (range, 1-9.4 years).

The diagnosis of AIC has been made on cholestatic patients with a liver biopsy compatible with $\mathrm{PBC}$, without AMA or M2 positivity. ANA were positive (titers $\geq 1: 160$ ) in all 17 patients. Anti-smooth muscle antibodies were positive (titer $\geq 1: 80$ ) in 9 patients. According to Scheuer's classification, 10 patients (58\%) had stage I-II and 7 $(42 \%)$ stage III-IV disease. The mean follow-up after diagnosis was 6.6 years (range, $1-7.8$ years).

Ultrasound, computed tomography and endoscopic retrograde cholangiography ruled out the possibility of biliary obstruction, when the latter was suspected. No patient had a family history of $\mathrm{CD}$, or IgA deficiency. One PBC patient was HbsAg positive and one PBC patient and two AIC patients were anti-HCV positive. One hundred Cretan adults selected at random from blood donors served as controls. Eighteen serum samples from symptomatic, biopsy-proven, AMA negative adults with CD were included in the study as methodological controls. Total IgA was measured in all CD patients and healthy controls to exclude IgA deficiency.

\section{Methods}

Two operators unaware of the clinical parameters performed the immunological tests. All PBC, AIC, CD and control sera were screened for AGAs, IgA-ARA, IgA-EMA and IgA-tTG. IgA- and IgG-AGA were screened by a commercial ELISA at a dilution of 1:50 (Alphadia SA/NV, Belgium). Values greater than $50 \mathrm{U} / \mathrm{mL}$ were considered positive. Results were considered doubtful and repeated for values between 45 and $50 \mathrm{U} / \mathrm{mL}$. For IgA-ARA R1-type, sera were tested by an indirect immunofluorescence (IIF) test at a 1:10 and 1:40 dilution, using rat liver, kidney and stomach as substrates (Sanofi Diagnostics Pasteur, France). Sera were screened for IgA-EMA by IIF, using both monkey oesophagus (Biosystems, Barcelona, Spain) and human umbilical cord (Eurospital SpA, Trieste, Italy) as substrates. Titers of $\geq 1: 5$ were considered positive. To avoid false-negative results, IgA-EMA were also evaluated at a 1:50 dilution. IgA-tTG were tested by a commercially available guinea-pig liver-derived tTG ELISA kit at a dilution of 1:101, according to manufacturers' instructions (QUANTA Lite $^{\mathrm{TM}}$ tTG ELISA, INOVA Diagnostics, San Di- 
ego, USA). The samples were classified as negative $(<20$ Units), weakly positive (20-30 Units) and strongly positive (>30 Units). Small intestinal biopsies were performed at endoscopy using endoscopic forceps. Four biopsy specimens from opposite sites of the distal duodenum were obtained and evaluated by one observer specialized in gastrointestinal tract pathology with regard to the villi/ crypts ratio and the number of intraepithelial lymphocytes (IELs) per 100 surface epithelial cells. Small bowel biopsies from the patients with $\mathrm{PBC}$ and AIC were evaluated blindly with those obtained from the $18 \mathrm{pa}-$ tients with untreated CD. When biopsy specimen revealed features of CD [29], namely, a lowering of the villous height to crypt depth ratio (normal, 3-5:1) and/or an increase in IELs (normal, 10-30 per 100 epithelial cells) a more detailed histological classification was applied [30].

Test results were compared using a $2 \times 2$ contingency table and chi-squared statistics. When appropriate, Fisher's exact test was used. $P$ values below 0.05 were considered significant.

\section{Results}

IgA class anti-gliadin antibodies and IgA class antibodies to tissue transglutaminase were detected with a significantly increased frequency in patients with both PBC and AIC as compared to healthy blood donors (Table 1). In contrast, none of the PBC and AIC patients was tested positive for anti-reticulin or anti-endomysial antibodies. Controls were tested negative for anti-reticulin, anti-endomysial and IgA class anti-tissue transglutaminase antibodies.

\section{PBC patients (Table 2)}

Both anti-gliadin antibodies were detected in 13 out of 62 patients with PBC $(21 \%$ vs. $3 \%$ in controls, $\mathrm{p}<0.001)$. IgA-AGA were tested positive in 12 patients $(19 \%$, p < 0.001 ), of whom 5 had stage I-II disease, and 7 had stage II-IV disease. IgA-AGA positivity was significantly more pronounced in patients with stage III-IV disease $(25 \%$ vs $14 \%, \mathrm{p}<0.05)$. IgA-tTG were detected in 6 patients $(10 \%), 3$ of whom had stage I-II disease and another 3 stage III-IV disease, while tested negative in all controls ( $\mathrm{p}$ $<0.001$ ). Serology was negative in the two patients with a superimposed viral hepatitis infection.

\section{AIC patients (Table 3)}

IgA-AGA were tested positive in 6 patients with AIC (35\% vs. $3 \%$ in controls, $\mathrm{p}<0.001)$, two with stage I-II disease and four with stage III-IV disease. IgA-AGA positivity was significantly more pronounced in patients with stage IIIIV disease $(57 \%$ vs $20 \%, \mathrm{p}<0.05)$. IgA-tTG were detected in 3 patients with AIC (18\%), two patients with stage I-II disease and one patient with stage III-IV disease, while tested negative in all controls $(\mathrm{p}<0.001)$. Serology was negative in two AIC patients with superimposed hepatitis C.

\section{CD patients}

All 18 patients with coeliac disease were tested positive for IgA-ARA, IgA-EMA and IgA-tTG, whereas 16 of them had also both IgA and IgG anti-gliadin antibodies.

\section{Healthy blood donors}

None of the 100 tested sera were found to be IgA-EMA or IgA-tTG positive. However AGAs were present in 3 individuals (IgA-AGA in one and IgG-AGA in two).

Table I: Prevalence (\%) of antibodies in patients and in controls

\begin{tabular}{|c|c|c|c|c|}
\hline & PBC $n=62(\%)$ & $A I C_{n}=17(\%)$ & BD $n=100$ & $C D n=18$ \\
\hline IgA-AGA & $12(19)^{*}$ & $6(35)^{*}$ & I & 18 \\
\hline IgG-AGA & $3(5)$ & - & 2 & 16 \\
\hline Any AGA & $13(2 \mid)^{*}$ & $6(35)^{*}$ & 3 & 18 \\
\hline Both AGAs & $2(3)$ & - & I & 16 \\
\hline IgA-ARA & - & - & - & 18 \\
\hline IgA-EMA & - & - & - & 18 \\
\hline IgA-tTG & $6(10)^{*}$ & $3(18)^{*}$ & - & 18 \\
\hline IgA-tTG and AGAs & $2(3)$ & $2(12)^{*}$ & - & 18 \\
\hline
\end{tabular}

$\mathrm{n}=$ number of patients; $*=$ where $p$ less than $0.05, \mathrm{PBC}=$ primary biliary cirrhosis; $\mathrm{AIC}=$ autoimmune cholangitis; $\mathrm{CD}=\mathrm{coeliac}$ disease; $\mathrm{BD}=$ blood donors; IgA-AGA = anti-gliadin antibodies, IgA class; IgG-AGA = anti-gliadin antibodies, IgG class; AGAs = anti-gliadin antibodies; IgA-ARA = IgA class anti-reticulin antibodies, RI type; IgA-EMA = anti-endomysial antibodies, IgA class; IgA-tTG = antibodies to tissue transglutaminase, IgA class 
Table 2: Antibody titers and intestinal biopsies in patients with primary biliary cirrhosis

\begin{tabular}{|c|c|c|c|c|c|c|c|}
\hline Patient & Disease stage $^{\mathrm{a}}$ & IgA-AGA & IgG-AGA & IgA-ARA & IgA-EMA & IgA-tTG & Intestinal biopsy \\
\hline $\mathrm{I}$. & $\mathrm{I}-\mathrm{II}$ & - & - & - & - & 49 & Normal \\
\hline 2. & I-II & 199 & 58,6 & - & - & 50 & Normal \\
\hline 3. & I-II & - & - & - & - & 25 & Normal \\
\hline 4. & I-II & 55 & - & - & - & - & ND \\
\hline 5. & I-II & 166 & - & - & - & - & Normal \\
\hline 6. & I-II & 200 & 200 & - & - & - & Normal \\
\hline 7. & $|-| \mid$ & 70 & - & - & - & - & ND \\
\hline 8. & III-IV & 244 & - & - & - & - & ND \\
\hline 9. & III-IV & 144 & - & - & - & - & ND \\
\hline 10. & III-IV & - & 67,4 & - & - & - & ND \\
\hline $\mathrm{II}$. & III-IV & - & - & - & - & 21 & ND \\
\hline 12. & III-IV & 106 & - & - & - & 32 & Normal \\
\hline 13. & III-IV & - & - & - & - & 28 & Normal \\
\hline 14. & III-IV & 97 & - & - & - & - & Normal \\
\hline 15. & III-IV & 53 & - & - & - & - & Normal \\
\hline 16. & III-IV & 57 & - & - & - & - & Normal \\
\hline 17. & III-IV & 253 & - & - & - & - & ND \\
\hline
\end{tabular}

according to Scheuer's classification; ND = not done

Table 3: Antibody titers and intestinal biopsies in patients with autoimmune cholangitis

\begin{tabular}{|c|c|c|c|c|c|c|c|}
\hline Patient & Disease stage $^{a}$ & IgA-AGA & $\begin{array}{l}\text { IgG- } \\
\text { AGA }\end{array}$ & $\begin{array}{l}\text { IgA- } \\
\text { ARA }\end{array}$ & $\begin{array}{l}\text { IgA- } \\
\text { EMA }\end{array}$ & IgA-tTG & Intestinal biopsy \\
\hline I. & I-II & 157 & - & - & - & 21,9 & Normal \\
\hline 2. & $|-| \mid$ & - & - & - & - & 26 & Normal \\
\hline 3. & I-II & 153 & - & - & - & - & ND \\
\hline 4. & III-IV & 55,9 & - & - & - & - & ND \\
\hline 5. & III-IV & 382 & - & - & - & 32 & Normal \\
\hline 6. & III-IV & 65 & - & - & - & - & Normal \\
\hline 7. & III-IV & 60 & - & - & - & - & Normal \\
\hline
\end{tabular}

according to Scheuer's classification; ND = not done

\section{Duodenal biopsies}

Overall, biopsies were performed in 10 out of 17 PBC patients (59\%) and 5 out of 7 AIC patients (71\%) tested IgAAGA and/or IgG-AGA and/or IgA-tTG positive. Five patients died shortly after testing positive and four patients refused any further investigation. None of the biopsied PBC and AIC patients had features suggestive of CD. Small bowel biopsies of our 18 patients with CD revealed partial villous atrophy (Marsh IIIa) in three, subtotal villous atrophy (Marsh IIIb) in eleven and total villous atrophy (Marsh IIIc) in four.

\section{Discussion}

In contrast to recent reports from Wales [8], Scandinavia [9], Northern Ireland [31], and Canada [32], the present study has not been able to demonstrate an increased risk of coeliac disease in this group of 62 Cretan patients with primary biliary cirrhosis. Our results are consistent with data from Sweden [11] and Italy [12,13], suggesting that if there is no clinical suspicion of CD, screening with antiendomysial antibodies should not be performed routinely in all patients with PBC.

A possible explanation relevant to these controversies could be the methodological differences in detecting and defining CD, like the different serological tests used for 
screening (AGAs and/or IgA-EMA), the degree of intestinal damage, or the spectrum of clinical presentation of $C D$ in patients studied. Patients with malabsorption, diarrhoea, weight loss, and total villous atrophy represent perhaps only $30-40 \%$ of the entire spectrum of gluten-sensitised individuals [19]. However, studies supporting the association between PBC and CD have included mainly symptomatic or complicated cases. In Kingham's et al study [8], CD in patients with $\mathrm{PBC}$ was sought by investigating features suggestive of malabsorption, a family history of $\mathrm{CD}$, the presence of AGAs, or the finding of otherwise unexplained haematinic deficiency. In Sorensen's et al paper [9], it is not clear whether all patients with CD were systematically evaluated for PBC. PBC was found in patients hospitalised for $\mathrm{CD}$, which presumably excluded patients with subclinical or silent disease. Furthermore, no information was available for patients treated as outpatients.

The inconsistencies between studies may also be attributed to the ethnic variability of $C D$ prevalence in the different populations. The prevalence of $\mathrm{CD}$ in Greece is currently unknown, because of the lack of official epidemiological data, but it is probably low. A crude estimation concerning of the prevalence of CD in Greece is provided from an endoscopic study from Athens, reporting one new case of unsuspected CD per 520 endoscopies [33]. When we retrospectively looked for, only 23 adult patients with symptomatic gluten-sensitive enteropathy were found over a 9 year period in a specialized University Unit, which is the main reference center for the total population of the island of Crete (approximately 500000 people).

We do recognize the fact that the size of the studied samples is not large enough to permit us to refute the presence of an association between CD and PBC safely. However, our inability to confirm this association is in agreement with recent data from large Italian series [13], consisted of 336 patients with CD and 65 cases with PBC. In this study, which can be assumed to be representative of the Mediterranean population, only one case of $\mathrm{PBC}$ among patients with CD was identified and no case of $\mathrm{CD}$ in the group of PBC.

Patients with autoimmune cholangitis were not included in the studies aiming to estimate the risk of CD in patients with PBC. In our small series, no case of CD was found among the 17 patients with autoimmune cholangitis and thus an association could not be established.

A possible limitation of our study may be the relatively low percentage of duodenal biopsies performed in patients with primary biliary cirrhosis tested positive for at least one antibody class. However, this was also the case in studies supporting the association. Our patients were screened for IgA-EMA by indirect immunofluorescence (IIF) test, using both monkey esophagus and human umbilical cord as substrates which have been shown to be highly sensitive and specific indicators of untreated coeliac disease $[16,17]$. Thus missing a case of CD in our patients with $\mathrm{PBC}$ seems rather unlikely. It was previously reported that the development of IgA-EMA depends on the severity of intestinal histopathology of CD and a subgroup of asymptomatic coeliacs negative for AGAs or IgAEMA will be under-diagnosed, especially those with minor tissue damage [30]. However, none of the studies supporting or failing to demonstrate the association have focused on this aspect.

In our series, $21 \%$ of $\mathrm{PBC}$ and $35 \%$ of AIC patients were tested positive for AGAs. Furthermore, IgA-AGA positivity was significantly more pronounced in patients with Scheuer's stage III-IV disease. Floreani et al [20] reported that IgA-AGA were found in 3.4\%, whereas both IgA and IgG-AGA in $6.8 \%$ of PBC patients. Likewise, Sjoberg et al [11] reported that the occurrence of false-positive AGAs in PBC patients was as high as $16 \%$. We therefore believe, as previously suggested $[11,20,21]$, that the presence of AGAs in PBC and AIC seems to be secondary to liver damage per se and represent a marker of non-specific immune reactivity. Finally, our results confirm the previously reported low specificity of guinea pig liver-derived tTG ELISA in patients with chronic liver disease [27]. We were unable to compare our results with those obtained by a human recombinant tTG ELISA as the latter is not currently commercially available in our country.

\section{Conclusions}

We confirmed the previously reported high prevalence of false-positive anti-gliadin and guinea pig liver-derived anti-tissue transglutaminase antibodies in patients with chronic liver disease. We were unable to confirm observations suggesting an over-representation of coeliac disease in patients with primary biliary cirrhosis. Our findings support the idea that in areas of low prevalence of $C D$, in the absence of clinical suspicion, screening all patients with $\mathrm{PBC}$ for coeliac disease should not be performed routinely.

\section{Competing interests}

none declared

\section{References}

I. Logan RF, Ferguson A, Finlayson ND, Weir DG: Primary biliary cirrhosis and coeliac disease: An association? Lancet 1978 I:230-233

2. Iliffe GD, Owen DA: An association between primary biliary cirrhosis and jejunal villous atrophy resembling celiac disease. Dig Dis Sci 1979, 24:802-806

3. Olsson R, Kagevi I, Rydeberg L: On the concurrence of primary biliary cirrhosis and intestinal villous atrophy. Scand J Gastroenterol 1982, 1 7:625-628 
4. Shanahan F, O' Regan PFB, Crowe JP: Primary biliary cirrhosis associated with coeliac disease. Ir Med J 1983, 76:282

5. Schrijver G, van Berge Henegouwen GP, Bronkhost FB: Gluten-sensitive coeliac disease and primary biliary cirrhosis syndrome. Neth J Med 1984, 27:218-22 I

6. Behr W, Barnert J: Adult celiac disease and primary biliary cirrhosis. Am J Gastroenterol 1986, 8 I:796-799

7. Lohr M, Lotterer E, Hahn EG, Fleig WF: Primary biliary cirrhosis associated with coeliac disease. Eur J Gastroenterol Hepatol 1994, 6:263-267

8. Kingham JPC, Parker DR: The association between primary biliary cirrhosis and coeliac disease: a study of relative prevalences. Gut 1998, 42:120-122

9. Sorensen HT, Thulstrup AM, Blomqvist P, Norgaard B, Fonager A, Ekbom A: Risk of primary biliary cirrhosis in patients with coeliac disease: Danish and Swedish cohort data. Gut 1999, 44:736738

10. Fidler HM, Butler P, Burroughs AK, McIntyre N, Bunn C, McMarrow $M$, Walmsley R, Dooley J: Co-screening for primary biliary cirrhosis and coeliac disease. Primary biliary cirrhosis and coeliac disease: a study of relative prevalences. Gut 1998, 43:300302

II. Sjoberg K, Lindgren S, Erikson S: Frequent occurrence of nonspecific gliadin antibodies in chronic liver disease. Endomysial but not gliadin antibodies predict coeliac disease in patients with chronic liver disease. Scand J Gastroenterol 1997, 32:1162-1167

12. Volta U, De Franceshi L, Molinaro N, Cassani F, Muratori L, Lenzi M, Bianchi FB, Czaja AJ: Frequency and significance of anti-gliadin and anti-endomysial antibodies in autoimmune hepatitis. Dig Dis Sci 1998, 43:2190-2195

13. Bardella MT, Quatrini M, Zuin M, Podda M, Cesarini L, Velio P, Bianchi $P$, Conte D: Screening patients with celiac disease for primary biliary cirrhosis and vice versa. Am J Gastroenterol 1997, 92:15241526

14. Heathcote J: Autoimmune cholangitis. Gut 1997, 40:440-442

15. Gogos CA, Nikolopoulou V, Zolota V, Siampi V, Vagenakis A: Autoimmune cholangitis in a patient with celiac disease: a case report and review of the literature. Hepatol 1999, 30:32I-324

16. Maki M: The humoral immune system in coeliac disease. Baillieres Clin Gastroenterol 1995, 9:231-249

17. Unsworth $D$ J: Serological diagnosis of gluten sensitive enteropathy. J Clin Pathol I 996, 49:704-7II

18. Maki M, Collin P: Coeliac disease Lancet 1997, 349:1755-1759

19. Fasano A, Catassi C: Current approaches to diagnosis and treatment of celiac disease: An evolving spectrum Gastroenterology 200I, | 20:636-5 |

20. Floreani A, Chiarimonte M, Venturini R, Plebani M, Martin A, Giacomini A, Naccarato R: Antigliadin antibody classes in chronic liver diseases. Ital ] Gastronetrol 1992, 24:457-460

21. Lindgren S, Sjoberg K, Erikson S: Unsuspected coeliac disease in chronic 'cryptogenic' liver disease. Scand ] Gastroenterol 1994, 29:66I-4

22. Dieterich W, Ehnis T, Bauer M, Donner P, Volta U, Rieken EO, Schuppan D: Identification of tissue transglutaminase as the autoantigen of celiac disease. Nat Med 1997, 3:797-80 I

23. Dieterich W, Laag E, Schopper $H$, Volta U, Ferguson A, Gillet $H$, Rieken EO, Schuppan D: Autoantibodies to tissue transglutaminase as predictors of celiac disease. Gastroenterology 1998, I 15:1317-1321

24. Sulkanen S, Haltunen T, Laurila K, Kolho KL, Korponay IR-Szabo, Sarnesto A, Savilahti E, Collin P, Maki M: Tissue transglutaminase Enzyme-Linked Immunoabsorbent Assay in detecting celiac disease. Gastroenterology 1998, I I 5: I322-1328

25. Lock RJ, Pitcher MCL, Unsworth DJ: IgA anti-tissue transglutaminase as a diagnostic marker of gluten sensitive enteropathy. J Clin Pathol 1999, 52:274-277

26. Biagi F, Ellis HJ, Yiannakou JY, Brusco G, Swift GL, Smith PM, Corazza GR, Ciclitira PJ: Tissue transglutaminase antibodies in celiac disease. Am J Gastroenterol 1999, 94:2187-2192

27. Carroccio A, Giannitrapani L, Soresi M, Not T, lacono G, Di Rosa C, Panfili E, Notarbatolo A, Montalto G: Guinea pig transglutaminase immunolinked assay does not predict coeliac disease in patients with chronic liver disease. Gut 200I, 49:506-5 I I

28. Scheuer PJ: Primary biliary cirrhosis: Chronic non-suppurative destructive cholangitis. Am J Pathol 1965, 46:387
29. American Gastroenterological Association Medical Position Statement: Celiac Sprue. Gastroenterology 200I, I 20:1522-I525

30. Rostami K, Kerckhaert J, Tiemessen R, von Blomberg ME, Meijer JWR, Mulder CJJ: Sensitivity of antiendomysium and antigliadin antibodies in untreated celiac disease: Disappointing in clinical practice. Am J Gastroenterol 1999, 94:888-894

31. Dickey W, McMillan SA, Callender ME: High prevalence of celiac sprue among patients with primary biliary cirrhosis. J Clin Gastroenterol 1997, 25:328-329

32. Gillett HR, Cauch-Dudek K, Jenny E, Heathcote EJ, Freeman HJ: Prevalence of IgA antibodies to endomysium and tissue transglutaminase in primary biliary cirrhosis. Can J Gastroenterol 2000, 14:665-666

33. Rokkas T, Karameris A: The usefulness of endoscopy in diagnosing celiac disease in Greece. Gastrointest Endosc 2000, 52:45 I

\section{Pre-publication history}

The pre-publication history for this paper can be accessed here:

http://www.biomedcentral.com/1471-230X/2/5/prepub

Publish with BioMed Central and every scientist can read your work free of charge

"BioMedcentral will be the most significant development for disseminating the results of biomedical research in our lifetime."

Paul Nurse, Director-General, Imperial Cancer Research Fund

Publish with BMC and your research papers will be:

- available free of charge to the entire biomedical community

- peer reviewed and published immediately upon acceptance

- cited in PubMed and archived on PubMed Central

- yours - you keep the copyright

Submit your manuscript here:

http://www.biomedcentral.com/manuscript/
BioMedcentral.com editorial@biomedcentral.com 